\title{
Occupational Stress, Coping Strategies, Health, and Well-Being Among University Academic Staff-An Integrative Review
}

\author{
Panshuo Shen ${ }^{1} \&$ Paul Slater ${ }^{1}$ \\ ${ }^{1}$ School of Nursing, Ulster University, Belfast, UK \\ Correspondence: Panshuo Shen, School of Nursing, Ulster University, Belfast, BT37 0QB, UK. E-mail: \\ shen-p@ulster.ac.uk
}

Received: June 28, 2021

Accepted: August 31, $2021 \quad$ Online Published: November 26, 2021

doi:10.5539/ies.v14n12p99

URL: https://doi.org/10.5539/ies.v14n12p99

\begin{abstract}
Occupational stress has been constantly rising among academics in universities globally, which affects their health and well-being. Although some studies reviewed occupational stress in academics, there has been less systematic evidence reviewed occupational stress of academic staff through the lens of the Transactional Model of Stress and Coping (TTSC). This integrative review aims to search, extract, appraise and synthesise recent evidence relating to occupational stress, coping strategies, health, and well-being of university academic staff. The Preferred Reporting Items for Systematic Review and Meta-Analysis (PRISMA) methodology provides a structure for searching and reporting the search outcomes. Primary studies relating to occupational stress, coping strategies, health, and well-being of academics in university published from 2010 onwards were selected from five databases, CINAHL, ERIC, PsycINFO, SCOPUS, and Web of Science in June 2020. Keywords included "stress", "coping strategy", "health", "well-being", "academics" and "university" in various combinations. The boolean operators "AND" and "OR" were also used. 17 out of 682 articles were included in this review. Most studies reported academics experienced moderate to high level of stress, and the heavy workload was one of the main stressors. Both positive and negative coping methods were used by academics to cope with stress. Occupational stress can contribute to poor mental health and decreased well-being of academics. This review can help to understand the work phenomenon of university academics and improve their health and well-being, which in turn can contribute to satisfaction and productivity within the educational institutes.
\end{abstract}

Keywords: occupational stress, coping strategies, health, well-being, academics, university

\section{Introduction}

Teaching is complicated in educational settings; it is marked by a large number of competencies and abilities that teachers have to acquire throughout their professional careers (Puertas, Zurita, Ubago, \& González, 2019), which resultantly puts high stress on them (Chaudhry, 2012). The academics, especially in the higher education institutions are recognised that they have experienced higher occupational stress compared to other populations (Adewale, Ghavifekr, \& Abdulsalam, 2017; Singh, Cross, Munro, \& Jackson, 2020). The statistics of Education Support (2019) showed $72 \%$ of teachers were stressed at work, and $63 \%$ were considering leaving their current position.

\subsection{Conceptualisation of Stress}

Stress remains a difficult concept to define, with researchers employing various models to explain aversive experiences of stress (Watts \& Robertson, 2011). Lazarus and Folkman's (1984) theoretical model (Transactional Stress and Coping Theory (TTSC)) (see Figure 1) of stress, coping and their relations to health and well-being was accepted widely (Lee \& Roberts, 2018). The individual appraisal is the basic component of the model; person-environment encounters and reactions to stress are mediated through a process of three types of cognitive appraisal: primary, secondary, and reappraisal (Lazarus \& Folkman, 1984). Primary appraisal is an essential assessment that evaluates the possible effects of the demands and resources on health and well-being. The secondary appraisal concerns possible coping options for overcoming the threat or challenge when a situation is evaluated as potentially stressful. As the situation develops further, reappraisal involves a constant re-evaluation about how stressful the situation is based on new information from the environment (Bell, Rajendran, \& Theiler, 2012). Obviously, stress is a complicated phenomenon in which health consequences are dependent upon each individual and how they deal with stressors (Bell et al., 2012). High stress leads to ill-being, poor health concerns 
and poor job satisfaction. TTSC provides a theoretical framework for capturing and analysing the facets of stress, coping strategies, health, and well-being among teachers (Walinga, 2010), which will be applied to direct, structure and develop the present review.

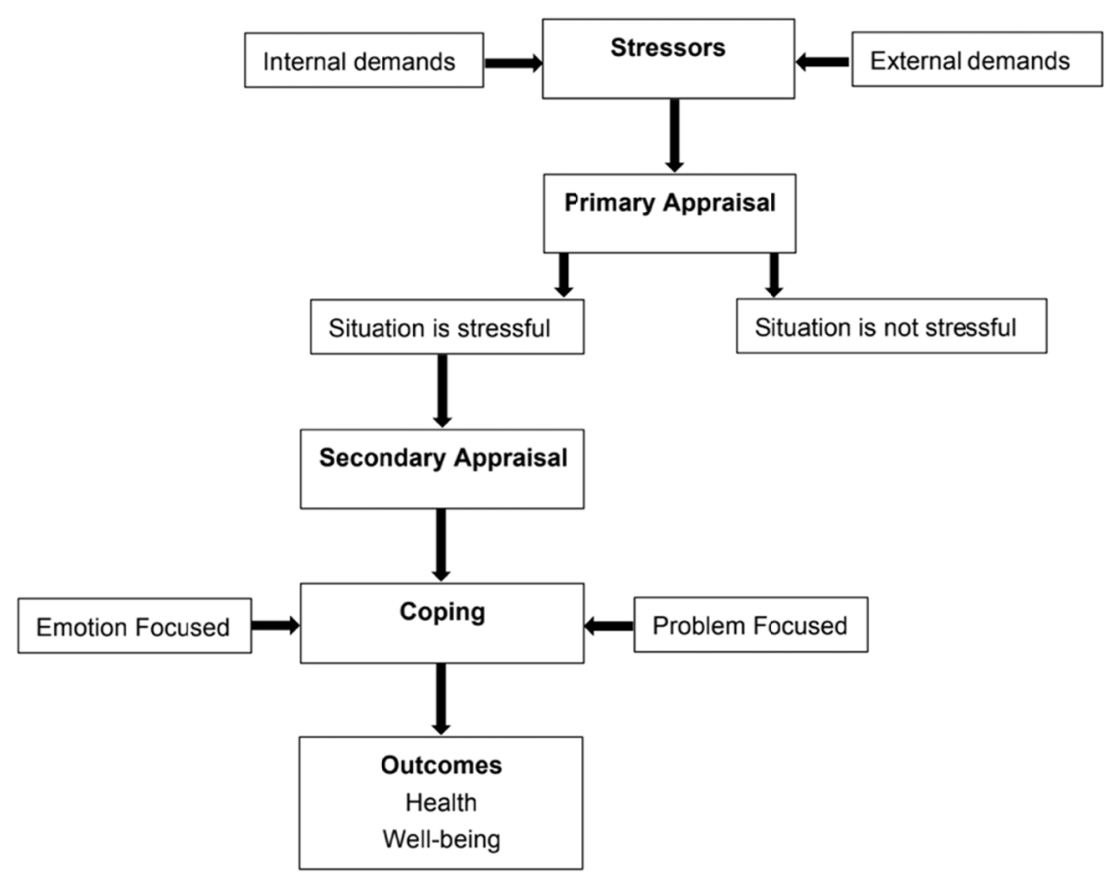

Figure 1. Transactional model of stress and coping (Lazarus \& Folkman, 1984)

\subsection{Occupational Stress in Academics}

Occupational stress is a leading major public health associated challenge and concern for all organizations (Lee, Joo, \& Choi, 2013; Imran, Ramzan, Khan, \& Maqsood, 2016; Basu, Qayyum, \& Mason, 2017). Over 550 million working days are lost annually in America due to work stress (The American Institute of Stress, 2018), and in the UK, 487,000 employees lost 11.3 million working days in 2013/14 (Buckely, 2014). The Health and Safety Executive (2019) reported that teachers have been highly influenced by stress at work. Kyriacou and Sutcliffe (1978) described the occupational stress in teachers as a response to the negative effect of the teacher's job, it constitutes a threat to the well-being and by coping mechanisms stimulated to lessen the perceived threat. Despite the "stress-free" inherent in academia previously, the academic staff in the tertiary education sector performs multiple roles include attending conferences, interacting with students, writing papers, and seeking funding (Singh, 2013; Bezuidenhout, 2015), which often lead to overwhelming stress and conflict (Ejue, 2013; Meng \& Wang, 2018). The enormous revolutions and frequent restructuring also have contributed to burdens of teaching, research, and publication for academics in the higher education system in the 21st century (Carton \& Fruchart, 2010; Quraishi, Aziz, \& Siddiquah, 2018).

\subsection{Coping Strategies in Academics}

Coping strategies can play a regulatory role in the relationship between stress and its outcomes (Jiang, Du, \& Dong, 2017); it refers to the cognitive effort used to manage the demands that an individual appraises as harm (Lazarus \& Folkman, 1984; Carton \& Fruchart, 2014). Coping strategies are considered adaptive when they are protective of health and well-being (Jiang \& Yang, 2016), and maladaptive when health and well-being are threatened (Holton, Barry, \& Chaney, 2016). However, coping responses are constantly changing, an adaptive coping strategy at one time can become maladaptive in a different situation (Bystritsky \& Kronemyer, 2014). Academic staff cope with stress differently (Melancon, 2014); Positive methods such as listening to music, conviviality with friends, and psychological assistance were taken by academics (Fadel et al., 2019), passive approaches including problematic alcohol consumption, substances use, smoking and poor diet (Carton \& Fruchart, 2014; Ruisoto, Vaca, López, Cacho, \& Fernández, 2017) were also taken by some individuals. Using alcohol and drug has been recognised as an adverse coping method (Holton et al., 2016), it also can be a beneficial 
adaption to moderate work stress conversely (Müller \& Schumann, 2011; Sattler, Sauer, Mehlkop, \& Graeff, 2013). However, there is a lack of evidence on this finding.

\subsection{Health and Well-Being of Academics}

Occupational stress contributes to ill-health among employees (Watts \& Robertson, 2011; Ejue, 2013; Shaw, 2014), which has led to a high rate of absenteeism, high staff turnover, low productivity, early retirement and strikes (Basu et al., 2017; Aquino, Lee, Spawn, \& Bishop, 2018). High levels of occupational stress also have been associated with increased risk of cardiovascular diseases (Basu et al., 2017), comparing to people with low work stress, people with high occupational stress had more than twice the chance of getting cardiovascular disease (Wilson, Conroy, \& Dorevitch, 2014). Occupational stress has the most significant effect on mental health (Holton et al., 2016). Mental health refers to a state of well-being in which individuals realise their own abilities can cope with stress in life (Lombardo, 2018; WHO, 2018). According to the statistic in America (ADAA, 2016), there were nearly 40 million Americans experience mental disorder, especially anxiety disorder annually, and they were among the most susceptible populations to endure mental health disorders due to their stress at work and inability to cope with stressors (Fan, Blumenthal, Watkins, \& Sherwood, 2015; Mérida-López, Extremera, \& Rey, 2017; Alvarado, 2019). The Health and Safety Executive (2020) reports that 0.6 million employees in the UK developed occupational illnesses such as depression, anxiety, and nervousness between years from 2018 to 2019, and there was number of higher education staff accessing occupational health services because of poor mental health (Guthrie et al., 2018; Weale, 2019). Academics in Australia were suffering from poor mental health due to long working hours (Fontinha et al., 2019), while the impact of occupational stress on the health of academic staff at higher educational institutions is not fully explored (S. Dreyer, L. Dreyer, \& Rankin, 2010). The general well-being of academics was decreased according to recent studies (Slišković \& Maslić-Seršič, 2011). A survey in the UK reported low well-being and higher stress amongst academics when compared with other staff members (Qudah, Davies, \& Deakin, 2019). High rates of stress-related health problem in work also impose a considerable social and financial burden on society (Skakon et al., 2010; Fontinha et al., 2019). The fact that millions of pounds have been paid out on teachers' mental and physical health in the UK (Mulholland, 2012); depression alone costs $\$ 44$ million in America yearly (Battams et al., 2014). Moreover, teachers in Queensland have increased mental health problems and claims which resulted in over $\$ 10$ million expenditure on them in five years (Worksafe Queensland, 2014).

\subsection{Rationale for Review}

Addressing occupational stress and promoting the health and well-being of academics are necessary for the sake of quality education (Quraishi et al., 2018). Although occupational stress has been studied in recent years, there is still an obvious lack of studies in higher education, especially in academics (Mark \& Smith, 2012; Li \& Kou, 2018). Furthermore, in recent years, there are many changes in the higher education environment, academic faculty face many new challenges in different countries; these issues are worthy of more systematic analysis and empirical research. In this circumstance, an up-to-date comprehensive review of the evidence is fundamentally imperative. TTSC will be used to guide the present study; it enables to organise the study topic. Hopefully, this study will lead to more future studies in the workplace of the university and develop policies and methods to improve the health and well-being of academics.

\subsection{Study Aims}

This integrative review aims to search, extract, appraise and synthesise recent evidence relating to occupational stress, coping strategies, health, and well-being of academics in higher education.

The review was guided by the following questions:

(1) What are the sources and levels of occupational stress in these studies?

(2) What are the main coping strategies used by academic staff to cope with occupational stress?

(3) What is the status of health or well-being within university academic staff?

(4) What is the relationship between occupational stress, health and well-being along with coping strategies?

\section{Methodology}

The integrative review process proposed by Whittemore and Knafl (2005) was used to guide this review. This review method allows the inclusion of diverse study designs, and it helps to facilitate a fully understanding of certain study concerns (Whittemore \& Knafl, 2005). According to them, the stages of an integrative review include problem identification, literature search, data evaluation, data analysis, and data presentation (Whittemore \& Knafl, 2005). The Preferred Reporting Items for Systematic Review and Meta-Analysis (PRISMA) (Moher, 
Liberati, Tetzlaff, Altman, \& Group P, 2010) methodology provided a structure for searching and reporting results. The theoretical framework of the Transactional Model of Stress and Coping (TTSC) (Lazarus \& Folkman, 1984) provided the structure to organise, analyse, and synthesise the findings of this integrative review.

\subsection{Search Strategy}

\subsubsection{Databases}

The systematic search was conducted in June 2020. Five electronic databases were used to search relevant studies: CINAHL, ERIC, PsycINFO, SCOPUS, and Web of Science. The coverage and time provided for each database shown in Table 1. The additional studies were identified with a search of relevant literature from the reference lists of selected studies.

Table 1. The focus and cover period of databases

\begin{tabular}{ccc}
\hline Database & Focus & Cover period \\
\hline CINAHL & General health and medicine & $1961-2020$ \\
ERIC(Educational Resources Information Centre) & Education & $1966-2020$ \\
PsycINFO & Behavioral science and psychology & $1806-2020$ \\
SCOPUS & Health sciences & $2004-2020$ \\
Web of Science & Science, social science & $1970-2020$ \\
\hline
\end{tabular}

\subsubsection{Search Terms and Boolean Operators}

Search terms were derived from the analysis of key studies which included "stress", "coping strategy", "health", "well-being", "academics" and "university", and their related search terms in various combinations. Table 2 shows the Example of the search strategy for CINAHL.

Table 2. Example of the search strategy for CINAHL

\begin{tabular}{cl}
\hline $\begin{array}{c}\text { Search } \\
\text { Number }\end{array}$ & \multicolumn{1}{c}{ Search String } \\
\hline S1 & (MH "Stress, Occupational+") \\
S2 & stress N3 (work or work-related or occupational or job or academic) \\
S3 & S1 OR S2 \\
S4 & (MH "Stress Management") \\
S5 & coping N3 (mechanism* or behavio\#r* or strateg* or skill* or method*) OR "stress management" \\
S6 & S4 OR S5 \\
S7 & health OR wellbeing OR well-being OR "life satisfaction" OR "quality of life" \\
& university N3 (staff or teacher* or lecturer* or professor* or researcher* or educator* or faculty or academician or employee*) \\
S8 & OR college N3 (staff or teacher* or lecturer* or professor* or researcher* or educator* or faculty or academician or employee*) \\
& OR "higher education" N3 (staff or teacher* or lecturer* or professor* or researcher* or educator* or faculty or academician or \\
& employee*) \\
S9 & S3 AND S8 \\
S10 & S3 AND S6 AND S8 \\
S12 & S3 AND S7 AND S8 AND S7 AND S8 \\
S13 & S3 AND S6 AND S7 AND S8
\end{tabular}

\subsection{Inclusion and Exclusion Criteria}

The inclusion criteria were: (a) full-text primary articles published in English in the period from 2010 to 2020, (b) studies published in peer-reviewed journals, (c) papers that used a qualitative, quantitative, or mixed-methods approach; for quantitative research, the study should explain the measurement tools, (d) studies including academics who worked only in higher education, and (e) studies clearly described findings related to occupational stress or stressors along with coping strategies, health or wellbeing of academic staff in higher education. This review excluded publications such as newspaper articles, conference papers, books, and dissertations. Papers that did not explicitly explore target themes (i.e., occupational stress, coping strategies, health, or wellbeing), and did not focus on academics in higher education settings were excluded. 


\subsection{Study Selection and Outcome}

The reference management software Refworks ${ }^{\circledR}$ was used to sort the articles. The initial search of the electronic databases resulted in a sample of 1541 articles (CINAHL $n=190$, ERIC $n=50$, PsycINFO $n=79$, SCOPUS $n=487$, Web of Science=735). Nine articles were found through the search of relevant literature from the reference lists. After duplication, 682 articles were identified for title and abstract. In light of the inclusion and exclusion criteria, 17 studies remained in this review. The process used to select articles was shown in Figure 2.

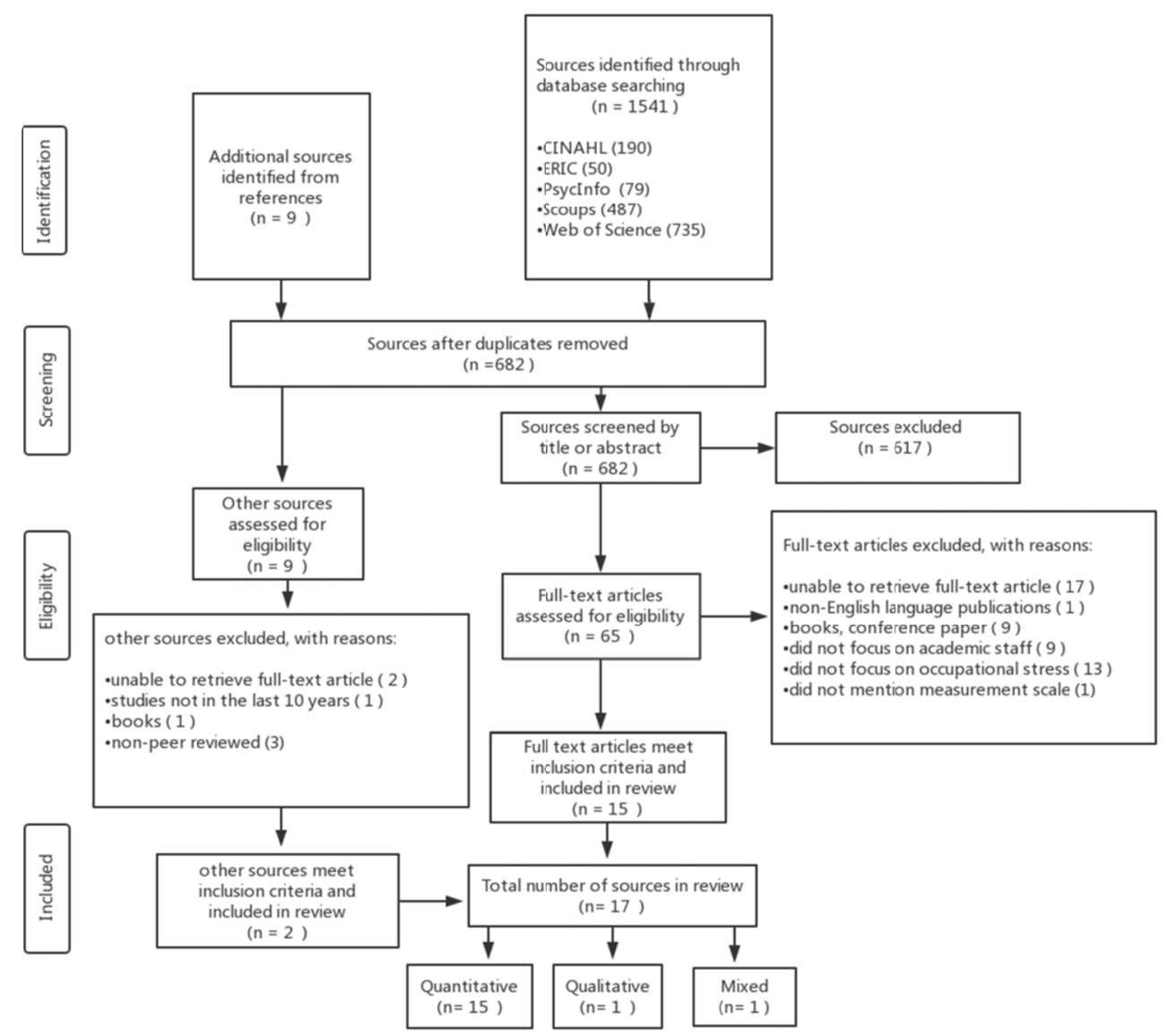

Figure 2. PRISMA diagram used for article selection

\subsection{Quality Appraisal}

Quantitative studies were systematically evaluated according to the cross-sectional studies checklist of STROBE (von Elm et al., 2007) as 15 out of 17 articles were employed a cross-sectional design. The items such as participants, sample size, statistical methods and results interpretation were appraised. Qualitative studies were appraised by the qualitative study checklist of Critical Appraisal Skills Programme (CASP) (CASP, 2018), items such as ethical issues, bias, and outcome analysis were evaluated.

\subsection{Data Extraction and Synthesis}

Extraction and synthesis of the studies were presented in Appendix A with consideration of author year, country, the purpose of study, methodology, population, sample size, setting, instrument, data collection method, main findings, and limitation. Main findings of included articles presented in Appendix B were sorted into the category of stress prevalence and level, stressors, coping strategies, health, and well-being.

\subsection{Analytic Strategy}

The data were analyzed with consideration of characteristics of the studies such as purpose, methods, and findings of the reviewed studies. Findings of selected studies were analysed within the framework of TTSC. Categories and themes were accomplished by organizing identified themes from the findings of each article within the TTSC. 


\section{Results}

\subsection{Characteristics of Studies}

There is an overview of the main characteristics of 17 studies included in this review (Appendix A), according to author, year, country, the purpose of study, methodology, population, sample size, setting, instrument, data collection method, and limitation.

\subsubsection{Setting}

Studies included in this review were conducted in several different countries. Four studies were conducted in China (Jiang et al., 2017; Li \& Kou, 2018; Meng \& Wang, 2018; Shen et al., 2014). Three studies occurred in the UK (Darabi, Macaskill, \& Reidy, 2017; Fontinha et al., 2019; Kinman, 2016). Two studies were from India (Priyadarshini, Ponnam, \& Banerjee, 2015; Sawhney \& Bansal, 2013), and two studies were from Brazil (Fadel et al., 2019; Tavares, Beck, Magnago, Zanini, \& Lautert, 2012). Australia (Bell et al., 2012), Canada (Catano et al., 2010), Saudi Arabia (Iqbal \& Kokash, 2011), Pakistan (Khan, Yusoff, \& Isa, 2016), Spain (Ruisoto et al., 2017) and Germany (Wiegel, Sattler, Göritz, \& Diewald, 2016) were represented by one study each.

\subsubsection{Method and Design}

$15(88.2 \%)$ studies utilised a quantitative approach, one (5.9\%) study utilized a qualitative approach, and one (5.9\%) study utilized a mixed-methods approach. Regarding the design adopted by the included studies; 15 studies were guided using a cross-sectional design, one study used an interview approach (Priyadarshini et al., 2015), and one study used both cross-sectional design and interview approach (Fadel et al., 2019).

\subsubsection{Sample Size and Sample Socio-demographics}

Of these included studies, 15 quantitative studies with sample sizes ranging from 50 to 5,445 academic staff members. The sample size of academics of one qualitative study and one mixed-methods study was 64 and 161 , respectively. Most studies were relatively more likely to report gender, age, education degree, academic rank, employment status, work experience and marital status of participants. Nevertheless, few studies reported ethnic group; and no study report a religious affiliation.

\subsubsection{Instrument}

In quantitative studies, the Effort-reward imbalance scale (Siegrist et al., 2004), Faculty Stress Index (FSI) (Gmelch, Wilke, \& Lovrich, 1986) and Perceived Stress Scale (PSS) (Cohen \& Williamson 1988) were the most common instruments used to measure stress. The Brief COPE Scale (Carver, 1997), General Health Questionnaire (GHQ) (Goldberg, 1972), and The Satisfaction with Life Scale (SWLS) (Diener, Emmons, Larsen, \& Griffin, 1985) were commonly adopted to measure coping strategies, health, and well-being, respectively. In a qualitative study, data were collected through in-depth interviews.

\subsubsection{Quality Assessment}

Most studies have clear aims, appropriate sample size, designs and outcome analysis. Some common limitations across the articles included a lack of consideration of confounders and existed bias. Some articles did not report ethical issues. The findings of most studies have the limitation of generalizability as the study is based on self-reporting in one single university in academics.

\subsection{Main Outcomes}

Synthesis of main findings was categorised into stress prevalence and level, stressors, coping strategies, health, and well-being (Appendix B).

\subsubsection{Prevalence and Level of Stress}

It can be inferred from ten papers that $22.3 \%$ (Shen et al., 2014) to $54.1 \%$ (Li \& Kou, 2018) academics were experiencing stress in tertiary education institutions. Most of academics experienced moderate levels of stress in the universities of Australia, China and India (Bell et al., 2012; Meng \& Wang, 2018; Sawhney \& Bansal, 2013). Two studies from China and Brazil reported a high stress level of academics (Li \& Kou, 2018; Tavares et al., 2012), and only one study showed moderate to very high stress levels experienced by academics in India (Priyadarshini et al., 2015). The variability in prevalence rates of stress may be due to the difference in measurement tools too.

\subsubsection{Stress in Relation to Socio-Demographics}

A number of socio-demographic characteristics had an impact on stress. Gender, age, employment status, income, academic rank, and teaching experience were found to be associated with increased occupational stress. A survey 
in Canadian universities found female academics have more risk of stress compared to male faculty (Catano et al., 2010), a similar result was also reported in higher education institutions in British (Fontinha et al., 2019). However, no differences in gender were identified on stress in the studies of Darabi et al. (2017), Li and Kou (2018) and Meng and Wang (2018) in some universities. Some findings reported age to be correlated with stress. This was supported by Meng and Wang (2018) who found that academics under 40 years old were suffering from a high level of occupational stress. In the studies of Catano et al. (2010) and Li and Kou (2018), academics between the ages of 36 and 45 were likely to experience higher stress. Older academic faculty (over 56) and younger academic faculty (below 35) were reported experienced a lower level of psychological stress (Fontinha et al., 2019; Li \& Kou, 2018). Temporary workers were experiencing high levels of stress (Fontinha et al., 2019); conversely, the full-time or part-time employment factor was reported did not make a statistically significant difference in the stress experienced by academic staff in Darabi et al.'s (2017) study. The academic rank and teaching experience factors reported by Meng and Wang (2018) showed that assistant professors experienced a higher level of stress than the associate professors and professors; and those working over ten years at the institution reported more stress compared to those with less working experience. These results are consistent with Tavares et al.'s (2012) but diverged from the finding of Darabi et al.'s (2017) study, which revealed no significant differences were found in terms of the level of seniority on the stress in the university.

\subsubsection{Stress Sources}

Stress was affected by a number of internal and external factors. These include:

External factors: Heavy workload as the main factor contributed to stress among academics was identified by most studies (Catano et al., 2010; Iqbal \& Kokash, 2011; Khan et al., 2016; Li \& Kou, 2018). Women, ages between 30 and 59, assistant and associate professor, and tenure track faculty reported high levels of stressors on workload compared to other groups (Catano et al., 2010). Only one study found the stress level of teachers who worked more than ten hours per day was less than that of teachers working less than eight hours per day (Li \& Kou, 2018). Administrative problems and unfair reward were identified as high levels of stressors among academics in a survey of Canadian university (Catano et al., 2010). Similarly, a study conducted by Fadel et al. (2019), Fontinha et al. (2019) and Meng and Wang (2018) also reported administrative affairs, salary and benefits issues were stressors in academics. Attending meetings, scientific research, publication targets and supervision of programs were recognised as stressors by several studies (Fadel et al., 2019; Iqbal \& Kokash, 2011; Meng \& Wang, 2018; Li \& Kou, 2018; Priyadarshini et al., 2015; Tavares et al., 2012). Priyadarshini et al. (2015) conducted a qualitative study among 64 professors in business schools in India, found that academics stated more stressors on increased changes, expectations, and competition in institutions.

Internal factors: The emotion of academics reflected their stress status (Khan et al., 2016). The lack of job control, role conflict and role clarity led to added stress (Catano et al., 2010). Ineffective relationships and communication with colleagues in work were regarded as high levels of stressors in the universities of the UK (Fontinha et al., 2019), Pakistan (Khan et al., 2016) and Saudi Arabia (Iqbal \& Kokash, 2011); only the study in Saudi Arabia drew that this source was the least pressured compared to other stressors.

\subsubsection{Coping Strategies}

Adaptive coping styles were used by academics in most studies. Academics were more likely to use problem-focused coping methods to manage stress in a British university Darabi et al. (2017). The positive cognitive appraisal was employed by the university academics in India (Priyadarshini et al., 2015), which aligned with the study of Darabi et al.'s (2017). One study showed that the psychological capital approach, which can be considered emotional-focused coping styles, was the preferred coping style in dealing with stress among academics in six Chinese universities (Shen et al., 2014). Transference such as exercise, attending activities and social interaction were the most popular coping strategies among academics in Brazil (Fadel et al., 2019), Saudi Arabia (Iqbal \& Kokash, 2011) and India (Priyadarshini et al., 2015). Maladaptive coping styles were only reported in two studies. Alcohol consumption was used by $82 \%$ of professors in a private university in Spain (Ruisoto et al., 2017), 13.1\% reported problematic alcohol drinking (Ruisoto et al., 2017). Male professors were more likely to have alcohol drinking than female professors (Ruisoto et al., 2017). As for drug use, Wiegel, Sattler, Göritz, and Diewald (2016) found that the academics in four German universities were using CE-drug to manage stress in work, but the prevalence of CE-drug use was very low.

\subsubsection{Health}

Health problems were the main outcomes of stress and negative coping strategies. The research of mental health of academics among these studies was more than physical health. $13 \%$ of academics reported psychological distress in Canadian universities (Catano et al., 2010). High levels of occupational stress of academics were correlated with 
greater levels of mental health issues (Catano et al., 2010; Kinman, 2016); it was also supported by Tavares et al.'s (2012) study, which found that nursing professors with high stress levels in the university have a great chance of getting minor psychiatric disorders. $43 \%$ of academic staff was in poor mental health in China (Li \& Kou, 2018); $50 \%$ academics experienced a mild level of anxiety, $49 \%$ had social dysfunction and depression symptoms in Pakistan (Khan et al., 2016). The prevalence of depressive symptoms (58.9\%) was even higher among Chinese academics according to Shen et al.'s (2014) study. Some socio-demographic characteristics significantly contributed to the health problems among academics. Female academics have more physical and psychological health problems than male faculty (Catano et al., 2010). However, this result was not consistent with Khan et al.'s (2016), which found that single, male faculty members were suffering from higher anxiety, depression and social dysfunction problems than female faculty. However, Shen et al. (2014) found that differences in depression for gender and marital status were not statistically significant. Young faculty members (20-40 years old) were reported experienced higher mental health disorders than other age groups in a survey in 12 Pakistan universities, while the study in 56 Canadian universities found youngest and oldest age groups of academics reported the fewest number of health problems than the age of 30-59 (Catano et al., 2010). The result of the study in Canadian universities aligned with Shen et al.'s (2014), which found that teachers with the age of 31 and 40 in Chinese universities had higher levels of depression than other age groups. Professors were found had a lower level of mental disorders than other academic ranks (Catano et al., 2010; Shen et al., 2014; Khan et al., 2016).

\subsubsection{Well-Being}

Few papers investigated the stress-related well-being of academics in higher institutions. A higher level of occupational stress did contribute to poorer well-being among academics (Catano et al., 2010; Bell et al., 2012; Fontinha et al., 2019; Sawhney \& Bansal, 2013). In an Indian university, college teachers reported had average life satisfaction levels (Sawhney \& Bansal, 2013), a similar finding was also found in a cross-sectional survey among academics in Australia; academics experienced mild levels of well-being and low levels of ill-being (Bell et al., 2012). Academics in Canada had a decreased positivity towards their well-being in the university according to Catano et al. (2010). Some socio-demographic characteristics also contribute to well-being among academics. Male faculty was likely to express higher levels of positive well-being than female faculty in two studies (Catano et al., 2010; Fontinha et al., 2019). According to Catano et al.'s (2010) study, tenure-track faculty reported better well-being than contract academics in Canadian universities (Catano et al., 2010); however, academics with tenure track in British universities were more likely to have poorer well-being than temporary workers (Fontinha et al., 2019). The youngest and oldest age groups reported better well-being than other age groups, assistant professors reported the least positive well-being compared to other academic ranks in the Catano et al.'s (2010) study in Canada. Factors included gender, employment status and academic rank of academics were found had no effect on mental health and well-being measures in Darabi et al.'s (2017) study in the UK.

\subsubsection{Relations}

Occupational stress of university teachers has a significant positive impact on negative coping style and negative impact on positive coping style directly (Darabi et al., 2017; Jiang et al., 2017). Stress predicted poorer mental health (Catano et al., 2010; Darabi et al., 2017; Kinman, 2016; Shen et al., 2014; Tavares et al., 2012) and well-being (Bell et al., 2012; Catano et al., 2010; Fontinha et al., 2019; Sawhney \& Bansal, 2013) among academics. Nevertheless, Jiang et al. (2017) supported that occupational stress can indirectly affect the mental health of academics through negative coping styles and positive coping styles. Problem-focused coping style was related to mental health and well-being positively (Darabi et al., 2017). Although emotion-focused coping has no association with mental health, it was positively correlated with the well-being of academics (Darabi et al., 2017). Conversely, dysfunctional coping style predicted poorer mental health while it has no relationship with well-being (Darabi et al., 2017). Overall, most studies addressed the relations of stress, coping, health, and well-being separately, there is no study that holistically investigate and synthesise their relationship.

\section{Discussion}

This integrative review aims to search, extract, appraise and synthesise recent evidence relating to occupational stress, coping strategies, health, and well-being of academics in higher education through the lens of TTSC. Most studies adopted the cross-sectional design and used a self-reported survey to collect data, while this method can limit the scope of the study, more current studies also employed it in the study. For instance, Soares et al. (2019) used a self-reported survey to collect the stress data of professors in a federal public university. The Faculty Stress Index (FSI) (Gmelch et al., 1986) was one of the most common instruments used to measure stress in the included studies. It was also used in the Moeller and Chung-Yan (2013) and Kang and Sidhu's (2015) studies to evaluate the stress in professors in Canadian university and Indian university, respectively. Standardization of an instrument to 
measure stress among academics would help examine stress comparatively and provide a more accurate picture worldwide.

It was apparent that most of academics in higher education were experiencing moderate to high levels of stress. Female academics experienced higher levels of stress than male faculty in most included studies. Similarly, recent evidence showed work-related stress was more prevalent among female faculty than among male faculty at university (Imran et al., 2016; HSE, 2019). Heavy workload as the main factor that contributed to stress among academics was identified by most studies reviewed, which is consistent with the finding conducted by Jawabri et al. (2019) in academics in the United Arab Emirates. Workplace bullying was reported as a stressful phenomenon that impacts the health and wellness of academics in higher education (Giorgi et al., 2016; Pheko, 2018; Hollis, 2019). Nevertheless, this stress source was not reported in the included 17 studies. Although there were some common stressors among academics, differences also existed. This may be caused by the education model and cultural background (Bhurtun et al., 2019) of different sectors. Using alcohol and drugs as negative coping strategies were reported in two studies in this review. However, Müller and Schumann (2011) and Sattler et al. (2013) reported the use of drugs among academics can be a beneficial adaption to moderate occupational stress. Apart from the above two approaches, smoking and an unhealthy diet were also commonly adopted by academics to cope with stress (Carton \& Fruchart, 2014). Occupational stress can indirectly affect the mental health and well-being of academics through negative coping style and positive coping style; high stress was related to greater levels of mental disorders and poor well-being. These findings were consistent with studies from Holton et al. (2016), Wenhua et al. (2016) and Achour et al. (2019), which showed that occupational stress has the most significant effect on mental health and well-being in academics in the higher education sector. Some included studies showed that socio-demographic characteristics such as gender, age and employment status significantly influence stress, coping strategies, health and well-being of academics, which aligned with the studies by Kataoka et al. (2014) and Kabito et al. (2020); their studies found that individual factors such as age, gender, education level, teaching experiences, position, and religious can potentially impact on stress in academics.

A few included studies used the TTSC model to study stress, coping styles and health among academics, while the findings of most studies supported the TTSC model that stress has an impact on health and well-being, and coping strategies play a regulatory role in the relationship between the stress and its outcomes.

\section{Strengths and Limitations of the Study}

This study contributed to the current understanding of occupational stress, coping strategies, health, and well-being among university academics. The search strategy and database selection were conducted after discussing with the librarian. This review followed a transparent and rigorous methodology, which can enhance the rigorousness of processing, reporting, integrating, and analysing the information. The construction of the results of the included studies was guided by the TTSC, which improve the clearness of the review. However, some limitations need to be considered. Potential selection and extraction bias can be resulted as the data extraction, quality evaluation, and analysis were conducted by one researcher. In the present study, only English language publications were included; some relative and valuable studies in non-English language may be potentially omitted. The present review included a large percentage of quantitative studies because of a lack of qualitative study in occupational stress in academics, which can limit the scope of the review. The dynamic nature of stress cannot be fully evaluated as most studies used a cross-sectional design. Further, recall bias and the risk of common method variance have resulted from the self-reported surveys in most articles. Small sample sizes in some included studies may threaten the generalisability of the findings. Additionally, the generalisability of the results also can be limited by the heterogeneity of tools and design in the studies reviewed. Subsequently, the relations of stress, coping, health, and well-being cannot be conducted easily, because there were only a few studies discussed them. Future research is needed to address these issues.

\section{Implications for Future Research}

The construct of the study is dynamic, the sole use of a cross-sectional approach and analysis could limit the scope of the study; employing a longitudinal design would be practical to track the development of occupational stress, coping, health, and well-being of academics. Sources of stress are more subjective, which differed from individuals; using the in-depth interview to collect data of stressors can help to understand the issues at hand and explore more aspects of stress experience from the subjective perception of academics. Guaranteeing an adequate sample size can enhance the ability to generalise the findings. There were few studies that investigated the specific occupational stress related socio-demographic characteristics, maladaptive coping strategies as well as mental health and well-being among university academic staff in the changing society. Their relationship has not been studied holistically. Therefore, a future study can be conducted under the guidance of these gaps. 


\section{Recommendations for Practice and Policy}

The findings of this review highlight the importance of using adaptive coping styles to deal with stress; thus, advocating a positive approach in dealing with occupational stress is important for academics (Jiang et al., 2017). Higher education institutions need to balance the effort and reward in work according to the stressors of academics and provide adequate resources (Iqbal \& Kokash, 2011). Investments and legislation of higher education should be addressed related to the benefits of academics (Khan et al., 2016).

\section{Conclusion}

This review expanded the current understanding of occupational stress, coping strategies, health, and well-being of academics in higher education. A majority of studies reported academics encountered moderate to high level of stress, and the heavy workload was one of the main stressors. Dealing with stress in work, academics were more likely to use problem-focused coping. Negative approaches such as drinking alcohol and using drugs were reported. Poor mental health and decreased well-being of academics were presented in most studies. Occupational stress can affect the mental health and well-being of academics through negative coping styles and positive coping styles. Socio-demographic characteristics such as gender, age and employment status can significantly influence stress, coping strategies, health, and well-being of academics. Future studies should investigate the specific occupational stress related socio-demographic characteristics, maladaptive coping strategies as well as mental health and well-being among university academics. This study can help to understand the work phenomenon of university academics and improve their health and well-being, which in turn can contribute to satisfaction and productivity within the educational institutes.

\section{References}

Achour, M., Azmi, I. B. A. G., Isahak, M. B., Nor, M. R. M., \& Yusoff, M. Y. Z. M. (2019). Job stress and nurses' well-being: Prayer and age as moderators. Community Mental Health Journal, 55(7), 1226-1235. https://doi.org/10.1007/s10597-019-00410-y

Adewale, A. S., Ghavifekr, S., \& Abdulsalam, I. (2017). Impact of stress on academic staff: Implication for higher education management and leadership. Malaysian Online Journal of Educational Management, 5(2), 75-91. https://doi.org/10.22452/mojem.vol5no2.5

Alvarado, S. C. (2019). Resilience, Mental Health, and Burnout Among School Teachers in Mexico. M.S. California State University, Long Beach. Retrieved from https://eric.ed.gov/?id=ED601696

Anxiety and Depression Association of America. (2016). Facts and statistics. Retrieved from https://adaa.org/about-adaa/press-room/facts-statistics

Aquino, E., Lee, Y.-M., Spawn, N., \& Bishop Royse, J. (2018). The impact of burnout on doctorate nursing faculty's intent to leave their academic position: A descriptive survey research design. Nurse Education Today, 69, 35-40. https://doi.org/10.1016/j.nedt.2018.06.027

Basu, S., Qayyum, H., \& Mason, S. (2017). Occupational stress in the ED: A systematic literature review. Emergency Medicine Journal: EMJ, 34(7), 441-447. https://doi.org/10.1136/emermed-2016-205827

Battams, S., Roche, A. M., Fischer, J. A., Lee, N. K., Cameron, J., \& Kostadinov, V. (2014). Health psychology and behavioral medicine. Health Psychology and Behavioral Medicine, 2(1), 983-1008. https://doi.org/10.1080/21642850.2014.954579

Bell, A. S., Rajendran, D., \& Theiler, S. (2012). Job Stress, Wellbeing, Work-Life Balance and Work-Life Conflict Among Australian Academics. E-Journal of Applied Psychology, 8(1), 25-37. https://doi.org/10.7790/ejap.v8i1.320

Bezuidenhout, A. (2015). Implications for academic workload of the changing role of distance educators. Distance Education, 36(2), 246-262. https://doi.org/10.1080/01587919.2015.1055055

Bhurtun, H. D., Azimirad, M., Saaranen, T., \& Turunen, H. (2019). Stress and coping among nursing students during clinical training: An integrative review. Journal of Nursing Education, 58(5), 266-272. https://doi.org/10.3928/01484834-20190422-04

Buckley, P. (2014). Stress-related and Psychological Disorders in Great Britain. London.

Burman, R., \& Goswami, T. G. (2018). A systematic literature review of work stress. International Journal of Management Studies, 5(3-9), 112-132. https://doi.org/10.18843/ijms/v5i3(9)/15

Bystritsky, A., \& Kronemyer, D. (2014). Stress and anxiety: Counterpart elements of the stress/anxiety complex. Psychiatric Clinics of North America, 37(4), 489-518. https://doi.org/10.1016/j.psc.2014.08.002 
Carton, A., \& Fruchart, E. (2014). Sources of stress, coping strategies, emotional experience: Effects of the level of experience in primary school teachers in France. Educational Review, 66(2), 245-262. https://doi.org/10.1080/00131911.2013.769937

Carver, C. S. (1997). You want to measure coping but your protocol's too long: Consider the Brief COPE. $\begin{array}{llll}\text { International Journal of } \quad \text { Behavioural } & \text { Medicine, }\end{array}$ https://doi.org/10.1207/s15327558ijbm0401_6

Catano, V. M., Francis, L., Haines, T., Kirpalani, H., Shannon, H., Stringer, B., \& Lozanski, L. (2010). Occupational stress in Canadian universities: A national survey. International Journal of Stress Management, 17(3), 232-258. https://doi.org/10.1037/a0018582

Chaudhry, A. Q. (2012). The Relationship between Occupational Stress and Job Satisfaction: The Case of Pakistani Universities. International Education Studies, 5(3), 212-221. https://doi.org/10.5539/ies.v5n3p212

Cohen, S., \& Williamson, G. (1988). Perceived stress in a probability sample of the United States. Social Psychology of Health, 31-67. Retrieved from https://psycnet.apa.org/record/1988-98838-002

Collinson, P. (2018). Finland is the Happiest Country in the World, Says UN Report. Retrieved from https://www.theguardian.com/world/2018/mar/14/finland-happiest-country-world-un-report

Critical appraisal skills programme (CASP). (2018). Checklists, C.A.S.P. Retrieved from https://casp-uk.net/casp-tools-checklists/

Darabi, M., Macaskill, A., \& Reidy, L. (2017). Stress among UK academics: Identifying who copes best. Journal of further and Higher Education, 41(3), 393-412. https://doi.org/10.1080/0309877X.2015.1117598

Darus, A., Azizan, F. L., \& Ahmad, F. (2016). Work stress, pay satisfaction, psychological empowerment and organisational commitment among academic staff. International Journal of Management Studies, 23(1), 51-72. https://doi.org/10.32890/ijms.23.1.2016.10466

De Silva, N., Samanmali, R., \& De Silva, H. L. (2017). Managing occupational stress of professionals in large construction projects. Journal of Engineering, Design and Technology, 15(4), 488-504. https://doi.org/10.1108/JEDT-09-2016-0066

Dehnad, S. V., Ghoreishizadeh, M. A. G. A., Falsefi, P., Negahdari, R., \& Babalou, A. R. (2016). The Comparison of Job Stress among Dental Professionals of Dentistry Faculty Members of Tabriz University. Asian Journal of Pharmaceutical Research and Health Care, 8(S1), 7-11. https://doi.org/10.18311/ajprhc/2016/7714

Diener, E., Emmons, R. A., Larsen, R. J., \& Griffin, S. (1985). The Satisfaction with Life Scale. Journal of Personality Assessment, 49, 71-75. https://doi.org/10.1207/s15327752jpa4901_13

Dreyer, S., Dreyer, L. I., \& Rankin, D. M. (2010). The Health and Wellbeing of Staff Members at a Tertiary Institution in New Zealand. ICHPER-SD Journal of Research, 5(1), 45-53. Retrieved from https://files.eric.ed.gov/fulltext/EJ903503.pdf

Education Support. (2019). Teacher wellbeing index 2019. Retrieved from https://www.educationsupport.org.uk/sites/default/files/teacher_wellbeing_index_2019.pdf

Ejue, J. B. (2013). Comparison of occupational stress among academics in federal and state universities in. Nigeria. Research in Education, 89(1), 85-89. https://doi.org/10.7227/RIE.89.1.8

Fadel, C. B., Flores, M. T., Brigola, S., Zanesco, C., Bordin, D., \& de Souza Martins, A. (2019). Work process and disposal of stress between teachers of biological sciences and health. Revista De Pesquisa: Cuidado é Fundamental Online, 11(4), 836-841. https://doi.org/10.9789/2175-5361.2019.v11i4.836-841

Fan, L. B., Blumenthal, J. A., Watkins, L. L., \& Sherwood, A. (2015). Work and home stress: Associations with. anxiety and depression symptoms. Occupational Medicine, 65(2), 110-116. https://doi.org/10.1093/occmed/kqu181

Fernandez-Sanchez, G., Bernaldo, M. O., Castillejo, A., \& Manzanero, A. M. (2014). Education for sustainable development in higher education: State of the art, barriers and challenges. Higher Learning Research Communications, 4(3), 3-11. https://doi.org/10.18870/hlrc.v4i3.157

Fontinha, R., Easton, S., \& Van Laar, D. (2019). Overtime and quality of working life in academics and non-academics: The role of perceived work-life balance. International Journal of Stress Management, 26(2), 173. https://doi.org/10.1037/str0000067 
Giorgi, G., Perminienė, M., Montani, F., Fiz-Perez, J., Mucci, N., \& Arcangeli, G. (2016). Detrimental effects of. workplace bullying: Impediment of self-management competence via psychological distress. Frontiers in Psychology, 7, 60. https://doi.org/10.3389/fpsyg.2016.00060

Gmelch, W., Wilke, P.K., \& Lovrich Jr, N. (1986). Dimensions of stress among university faculty: Factor-analytic results from a national study. Research in Higher Education, 24(3), 266-286. https://doi.org/10.1007/BF00992075

Goldberg, D. P. (1972). The detection of psychiatric illness by questionnaire: A technique for the identification and. assessment of non-psychotic psychiatric illness. London, New York: Oxford University Press.

Guthrie, S., Lichten, C. A., Van Belle, J., Ball, S., Knack, A., \& Hofman, J. (2018). Understanding mental health in the research environment: A Rapid Evidence Assessment. Rand Health Quarterly, 7(3), 2. https://doi.org/10.7249/RR2022

Health and Safety Executive (HSE). (2019). Work-related stress, anxiety or depression statistics in Great Britain 2019. Retrieved from https://www.hse.gov.uk/statistics/causdis/stress.pdf

Health and Safety Executive (HSE). (2020). Health and Safety Executive Annual Report and Accounts 2019/20. Retrieved from https://www.hse.gov.uk/aboutus/reports/ara-2019-20.pdf?new

Hollis, L. P. (2019). Analysis of Faculty Wellness and Workplace Bullying. Retrieved from https://eric.ed.gov/?id=ED593910

Holton, M. K., Barry, A. E., \& Chaney, J. D. (2016). Employee stress management: An examination of adaptive and maladaptive coping strategies on employee health. Work, 53(2), 299-305. https://doi.org/10.3233/WOR-152145

Imran, S. S., Ramzan, M., Khan, K. W., \& Maqsood, I. (2016). Occupational stress among faculty of Wah Medical. College: A comparative study. Rawal Medical Journal, 41(2), 234-237. http://rmj.org.pk/fulltext/27-1441194947.pdf

Iqbal, A., \& Kokash, H. (2011). Faculty perception of stress and coping strategies in a Saudi Private University: An exploratory study. Journal of International Education Studies, 4(3), 137-49. https://doi.org/10.5539/ies.v4n3p137

Jawabri, A., Alarmoti, A., \& Mohammed, M. (2019). Job stress and satisfaction among academic staffs in public universities: An empirical study in the United Arab Emirates (UAE). Management Science Letters, 9(7), 973-986. https://doi.org/10.5267/j.msl.2019.4.007

Jeffrey, K., Mahony, S., Michaelson, J., \& Abdallah, S. (2014). Well-being at work: A review of the literature. Retrieved from https://neweconomics.org/2014/03/wellbeing-at-work

Jiang, X., Du, J., \& Dong, R. (2017). Coping style, job burnout and mental health of university teachers of the millennial generation. Eurasia Journal of Mathematics, Science and Technology Education, 13(7), 3379-3392. https://doi.org/10.12973/eurasia.2017.00734a

Kabito, G. G., Wami, S. D., Chercos, D. H., \& Mekonnen, T. H. (2020). Work-related Stress and Associated Factors. among Academic Staffs at the University of Gondar, Northwest Ethiopia: An Institution-based Cross-sectional Study. Ethiopian Journal of Health Sciences, 30(2), 223. https://doi.org/10.4314/ejhs.v30i2.10

Kang, L. S., \& Sidhu, H. (2015). Identification of stressors at work: a study of university teachers in India. Global Business Review, 16(2), 303-320. https://doi.org/10.1177/0972150914564421

Kataoka, M., Ozawa, K., Tomotake, M., Tanioka, T., \& King, B. (2014). Occupational stress and its related factors among university teachers in Japan. Health, 6, 299-305. https://doi.org/10.4236/health.2014.65043

Khan, A., Yusoff, R. B. M., \& Isa, K. B. (2016). Examining Linkages between Psychological Health Problems, Socio-Demographic Characteristics and Workplace Stressors in Pakistan's Academia. International Education Studies, 9(6), 108-119. https://doi.org/10.5539/ies.v9n6p108

Kinman, G. (2016). Effort-reward imbalance and overcommitment in UK academics: implications for mental health, satisfaction and retention. Journal of Higher Education Policy and Management, 38(5), 504-518. https://doi.org/10.1080/1360080X.2016.1181884

Kyriacou, C., \& Sutcliffe, J. (1978). A model of teacher stress. Educational Studies, 4, 1-6. https://doi.org/10.1080/0305569780040101 
Lawal, N. A., \& Wahab, T. I. (2011). Education and economic growth: The Nigerian experience. Journal of Emerging Trends in Economics and Management Sciences, 2(3), 225-231. Retrieved from https://hdl.handle.net/10520/EJC134170

Lazarus, R. S., \& Folkman, S. (1984). Stress, appraisal, and coping. New York, NY: Springer.

Lee, E., \& Roberts, L. J. (2018). Between individual and family coping: a decade of theory and research on couples coping with health-related stress. Journal of Family Theory \& Review, 10(1), 141-164. https://doi.org/10.1111/jftr.12252

Lee, J. S., Joo, E. J., \& Choi, K. S. (2013). Perceived stress and self - esteem mediate the effects of work related. stress on depression. Stress and Health, 29(1), 75-81. https://doi.org/10.1002/smi.2428

Li, W., \& Kou, C. (2018). Prevalence and correlates of psychological stress among teachers at a national key comprehensive university in China. International Journal of Occupational and Environmental Health, 24(1-2), 7-16. https://doi.org/10.1080/10773525.2018.1500803

Lombardo, P., Jones, W., Wang, L., Shen, X., \& Goldner, E. M. (2018). The fundamental association between mental health and life satisfaction: results from successive waves of a Canadian national survey. $B M C$ Public Health, 18, 342. https://doi.org/10.1186/s12889-018-5235-x

Mark, G., \& Smith, A. P. (2012) Effects of occupational stress, job characteristics, coping, and attributional style on the mental health and job satisfaction of university employees. Anxiety, Stress and Coping, 25(1), 63-78. https://doi.org/10.1080/10615806.2010.548088

Meng, Q., \& Wang, G. (2018). A research on sources of university faculty occupational stress: A Chinese case study. Psychology Research and Behavior Management, 11, 597. https://doi.org/10.2147/PRBM.S187295

Mérida-López, S., Extremera, N., \& Rey, L. (2017). Emotion-regulation ability, role stress and teachers' mental. health. Occupational Medicine, 67(7), 540-545. https://doi.org/10.1093/occmed/kqx125

Moeller, C., \& Chung-Yan, G. A. (2013). Effects of social support on professors' work stress. International. Journal of Educational Management, 27(3), 188-202. https://doi.org/10.1108/09513541311306431

Moher, D., Liberati, A., Tetzlaff, J., Altman, D. G., \& The PRISMA Group. (2010). Preferred reporting items for systematic reviews and meta-analyses: The PRISMA statement. International Journal of Surgery, 8, 336-341. https://doi.org/10.1016/j.ijsu.2010.02.007

Mudrak, J., Zabrodska, K., Kveton, P., Jelinek, M., Blatny, M., Solcova, I., \& Machovcova, K. (2016). Occupational well-being among university faculty: A job demand resources model. Research in Higher Education, 59, 325-348. https://doi.org/10.1007/s11162-017-9467-x

Mulholland, H. (2012). Millions paid out to teachers for classroom assaults and accidents. Retrieved from https://www.theguardian.com/education/2012/apr/05/teachers-classroom-assaults-accidents

Müller, C. P., \& Schumann, G. (2011). Drugs as instruments: A new framework for non-addictive psychoactive drug use. Behavioral and Brain Sciences, 34, 293-310. https://doi.org/10.1017/S0140525X11000057

Pheko, M. M. (2018). Autoethnography and cognitive adaptation: Two powerful buffers against the negative. consequences of workplace bullying and academic mobbing. International Journal of Qualitative Studies on Health and Well-being, 13, 1459134. https://doi.org/10.1080/17482631.2018.1459134

Priyadarshini, C., Ponnam, A., \& Banerjee, P. (2015). Role Stress and Coping Among Business School Professors: A Phenomenological Study. Qualitative Report, 20(12), 2050-2066. https://doi.org/10.46743/2160-3715/2015.2434

Puertas Molero, P., Zurita Ortega, F., Ubago Jiménez, J. L., \& González Valero, G. (2019). Influence of emotional. intelligence and burnout syndrome on teacher's well-being: a systematic review. Social Sciences, 8(6), 185. https://doi.org/10.3390/socsci8060185

Qudah, S., Davies, J., \& Deakin, R. (2019). Can we get more satisfaction? Improving quality of working life survey results in UK universities. Perspectives: Policy and Practice in Higher Education, 23(2-3), 39-47. https://doi.org/10.1080/13603108.2018.1534758

Quraishi, U., Aziz, F., \& Siddiquah, A. (2018). Stress and coping strategies of university teachers in Pakistan. Pakistan Journal of Education, 35(2), 193-206. https://doi.org/10.30971/pje.v35i2.550

Renn, C. (2018). Teacher Wellbeing Index 2018 highlights stress epidemic and rising mental health issues across the sector. Retrieved from https://www.educationsupport.org.uk/about-us/press-centre/teacher-wellbeing- 
index-2018-highlights-stress-epidemic-and-rising-mental

Ruisoto, P., Vaca, S. L., López-Goñi, J. J., Cacho, R., \& Fernández-Suárez, I. (2017). Gender differences in problematic alcohol consumption in university professors. International Journal of Environmental Research and Public Health, 14(9), 1069. https://doi.org/10.3390/ijerph14091069

Sattler, S., Sauer, C., Mehlkop, G., \& Graeff, P. (2013). The rationale for consuming cognitive enhancement drugs in university students and teachers. PLoS ONE, 8(7), e68821. https://doi.org/10.1371/journal.pone.0068821

Sawhney, N., \& Bansal, S. (2013). Life satisfaction of professional college teachers in relation to their stress level. Indian Journal of Health and Wellbeing, 4(2), 272-277. Retrieved from http://www.iahrw.com/index.php/home/journal_detail/19\#list

Shaw, C. (2014). Overworked and isolated-work pressure fuels mental illness in academia. Retrieved from https://www.theguardian.com/uk

Shen, X., Yang, Y., Wang, Y., Liu, L., Wang, S., \& Wang, L. (2014). The association between occupational stress and depressive symptoms and the mediating role of psychological capital among Chinese university teachers: a cross-sectional study. BMC Psychiatry, 14(1), 329. https://doi.org/10.1186/s12888-014-0329-1

Siegrist, J., Starke, D., Chandola, T., Godin, I., Marmot, M., Niedhammer, I., \& Peter, R. (2004) The measurement of effort-reward imbalance at work: European comparisons. Social Science and Medicine, 58, 1483-1499. https://doi.org/10.1016/S0277-9536(03)00351-4

Singh, A.K. (2013). Study of occupational stress job satisfaction and mental health of teachers. Retrieved from http://shodhganga.inflibnet.ac.in:8080/jspui/handle/10603/167030

Singh, C., Cross, W., Munro, I., \& Jackson, D. (2020). Occupational stress facing nurse academics-A mixed-methods systematic review. Journal of Clinical Nursing, 29(5-6), 720-735. https://doi.org/10.1111/jocn.15150

Skakon, J., Nielsen, K., Borg, V., \& Guzman, J. (2010). Are leaders' well-being, behaviours and style associated with the affective well-being of their employees? A systematic review of three decades of research. Work and Stress, 24(2), 107-139. https://doi.org/10.1080/02678373.2010.495262

Slišković, A., \& Maslić Seršič, D. (2011). Work stress among university teachers: Gender and position differences. Archives of Industrial Hygiene and Toxicology, 62(4), 299-307. https://doi.org/10.2478/10004-1254-62-2011-2135

Soares, M. B., Mafra, S. C. T., \& de Faria, E. R. (2019). Factors associated with perceived stress among professors at a federal public university. Revista Brasileira De Medicina do Trabalho, 17(1), 90. https://doi.org/10.5327/Z16794435520190280

Sun, W., Wu, H., \& Wang, L. (2011). Occupational stress and its related factors among university teachers in China. Journal of Occupational Health, 53(4), 280. https://doi.org/10.1539/joh.10-0058-OA

Tavares, J. P., Beck, C. L. C., Magnago, T. S. B. S., Zanini, R. R., \& Lautert, L. (2012). Minor psychiatric disorders among nurse's university faculties. Revista Latino-Americana De Enfermagem, 20(1), 175-182. https://doi.org/10.1590/S0104-11692012000100023

Terán, R., \& Botero, Á. (2011). El capitalismo organizacional: una mirada a la calidad de vida laboral en la docencia universitaria. Cuadernos de Administración, 27(46), 9-21. https://doi.org/10.25100/cdea.v27i46.79

Urbina-Garcia, A. (2020). What do we know about University Academics' Mental Health? A Systematic Literature Review. Stress and Health, 2020, 1-23. https://doi.org/10.1002/smi.2956

Von Elm, E., Altman, D. G., Egger, M., Pocock, S. J., Gøtzsche, P. C., \& Vandenbroucke, J. P. (2007). The Strengthening the Reporting of Observational Studies in Epidemiology (STROBE) statement: Guidelines for reporting observational studies. Annals of Internal Medicine, 147(8), 573-577. https://doi.org/10.1016/S0140-6736(07)61602-X

Walinga, J. (2010). Stress, health, and coping. Introduction to psychology, 871-905. Retrieved from https://openpress.usask.ca/introductiontopsychology/chapter/stress-and-coping/

Watts, J., \& Robertson, N. (2011). Burnout in university teaching staff: A systematic literature review. Educational Research, 53(1), 33-50. https://doi.org/10.1080/00131881.2011.552235

Weale, S. (2019). Higher education staff suffer "epidemic" of poor mental health. Retrieved from 
https://www.theguardian.com/education/2019/may/23/higher-education-staff-suffer-epidemic-of-poor-ment al-health

Wenhua, L., Licheng, R., \& Ru, Z. (2016). Exploration on the relationship between occupational stress and well-being of the junior administrative staff in universities of china from the perspective of social network. Revista De Cercetare Si Interventie Sociala, 53, 145. Retrieved from https://www.proquest.com/openview/ 4a8baaf891 ed584bbf929f119a82fcf1/1?pq-origsite $=$ gscholar\&cbl $=2031098$

Whitley, R., \& Gläser, J. (2014). The impact of institutional reforms on the nature of universities as organisations. $\begin{array}{lllll}\text { Research in the Sociology of } & \text { Organizations, } & 42, & 19-49 .\end{array}$ https://doi.org/10.1108/S0733-558X20140000042000

Whittemore, R., \& Knafl, K. (2005). The integrative review: updated methodology. Journal of Advanced Nurse, 52(5), 546-553. https://doi.org/10.1111/j.1365-2648.2005.03621.x

Wiegel, C., Sattler, S., Göritz, A. S., \& Diewald, M. (2016). Work-related stress and cognitive enhancement among university teachers. Anxiety, Stress, and Coping, 29(1), 100-117. https://doi.org/10.1080/10615806.2015.1025764

Wilson, M. D., Conroy, L. M., \& Dorevitch, S. (2014). Occupational stress and subclinical atherosclerosis: A systematic review. International Journal of Occupational and Environmental Health, 20(4), 271-280. https://doi.org/10.1179/2049396714Y.0000000076

Worksafe Queensland. (2013). Queensland teachers most stressed workers. Retrieved from https://www.worksafe.qld.gov.au/education/articles/queensland-teachers-most\%20stressed-workers

World Health Organization. (2018). Mental health atlas 2017. Cairo: WHO Regional Office for the Eastern. Retrieved from https://apps.who.int/iris/handle/10665/327491 


\section{Appendix A}

\section{Characteristics of included articles}

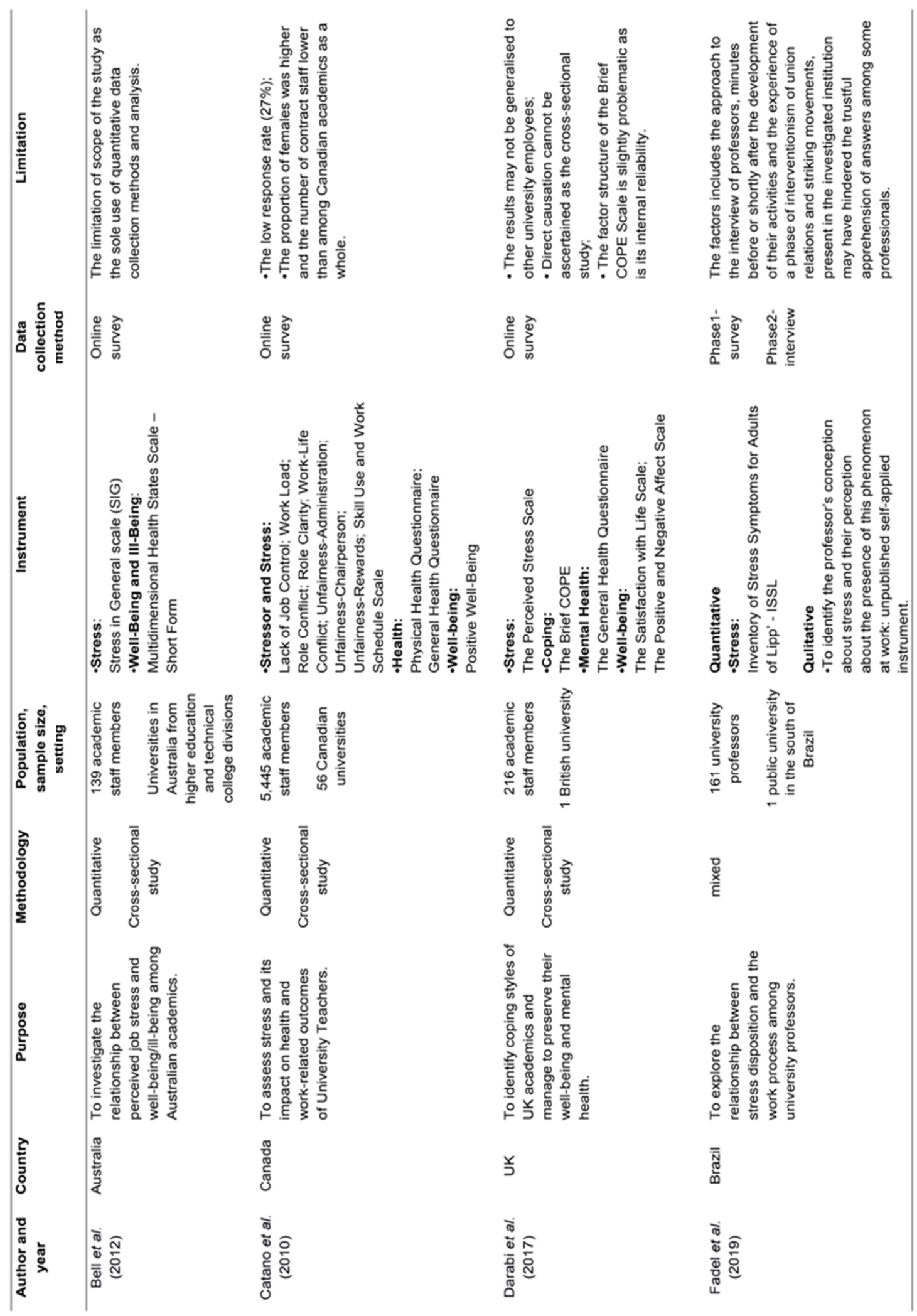




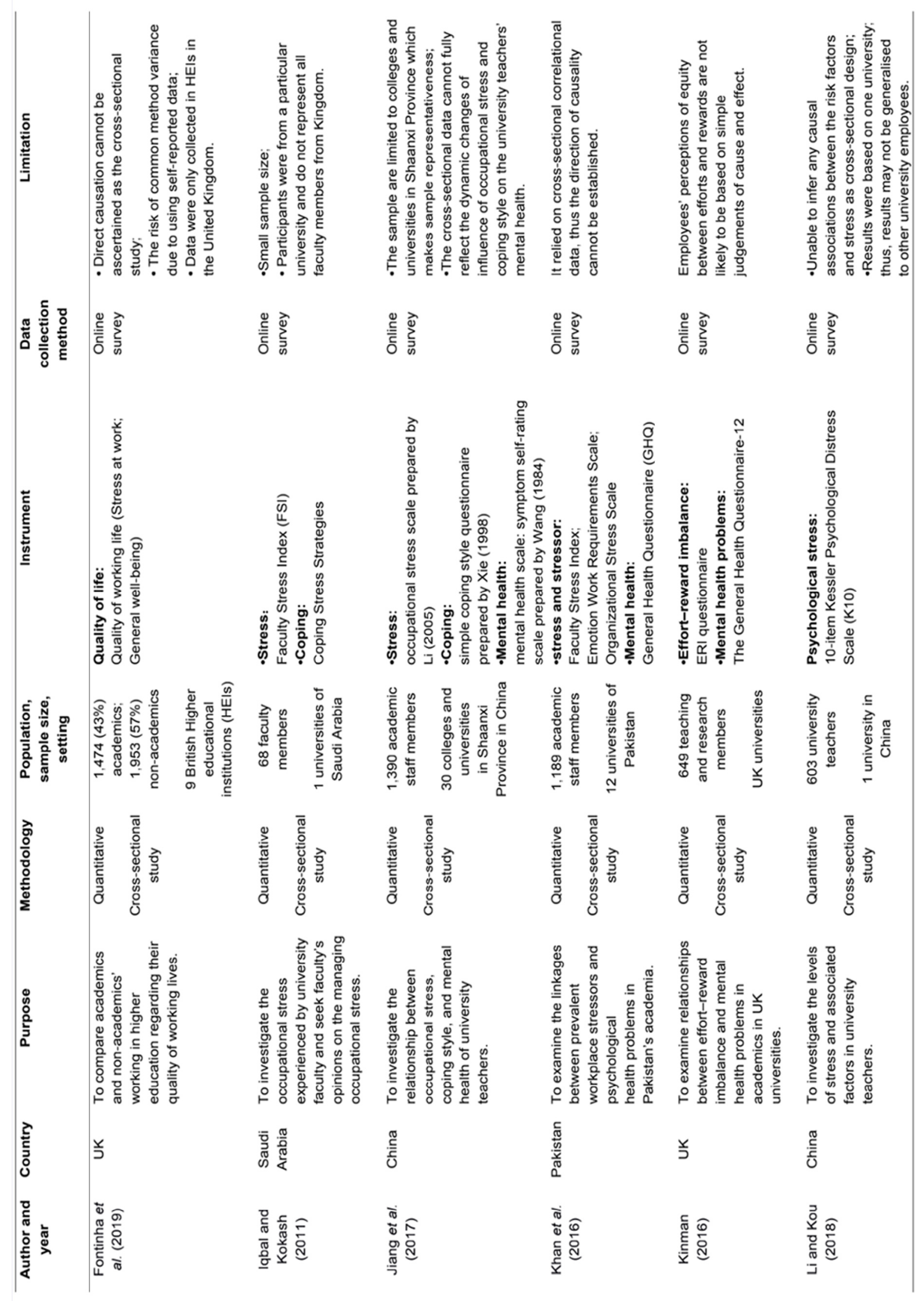




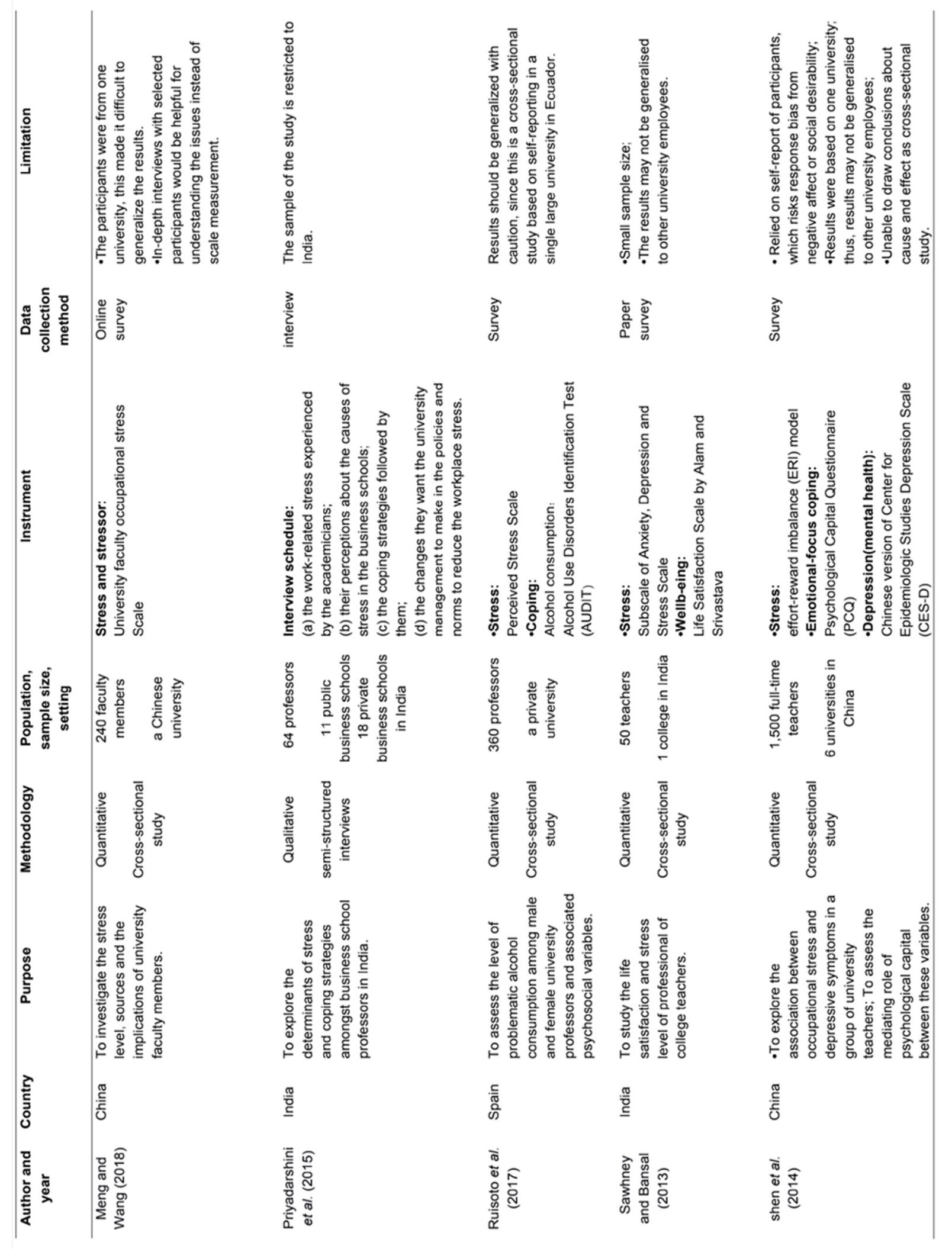




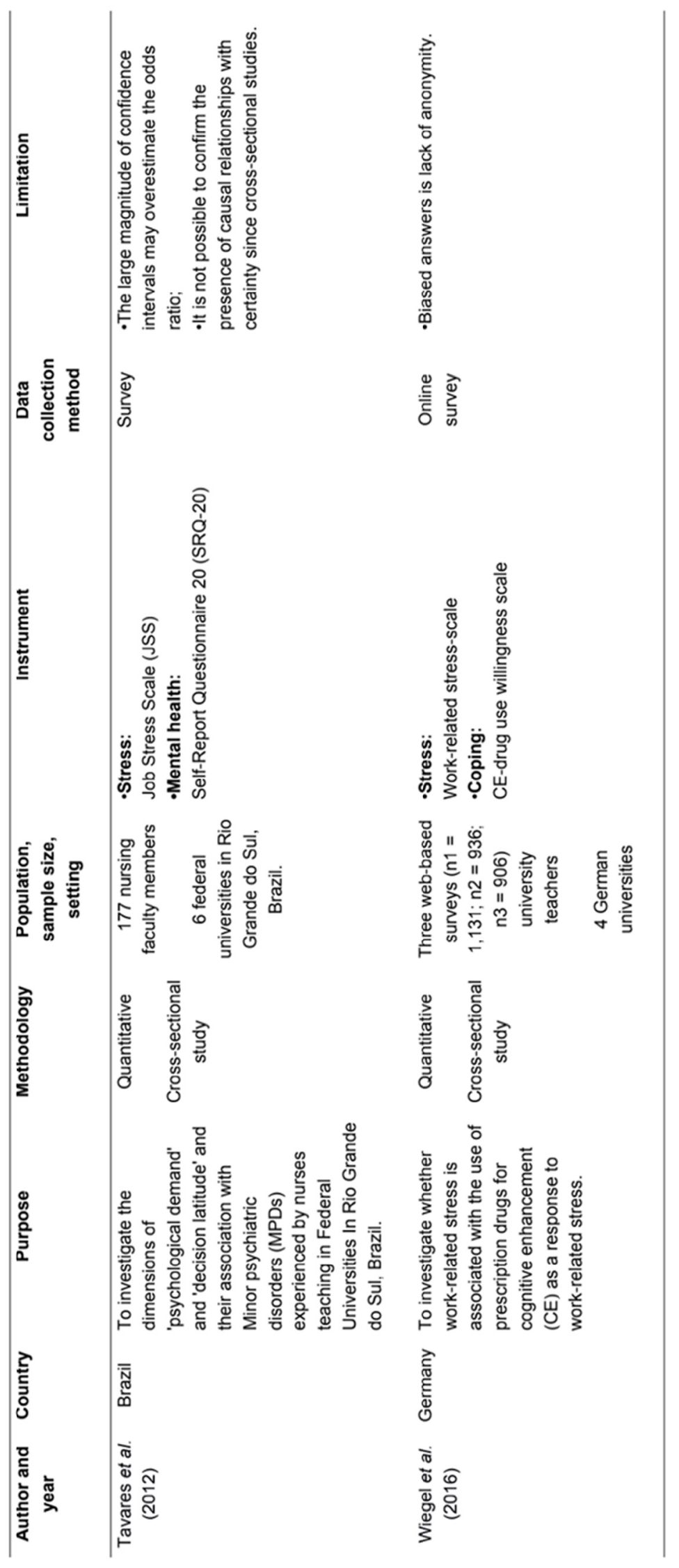




\section{Appendix B}

Main findings of included articles

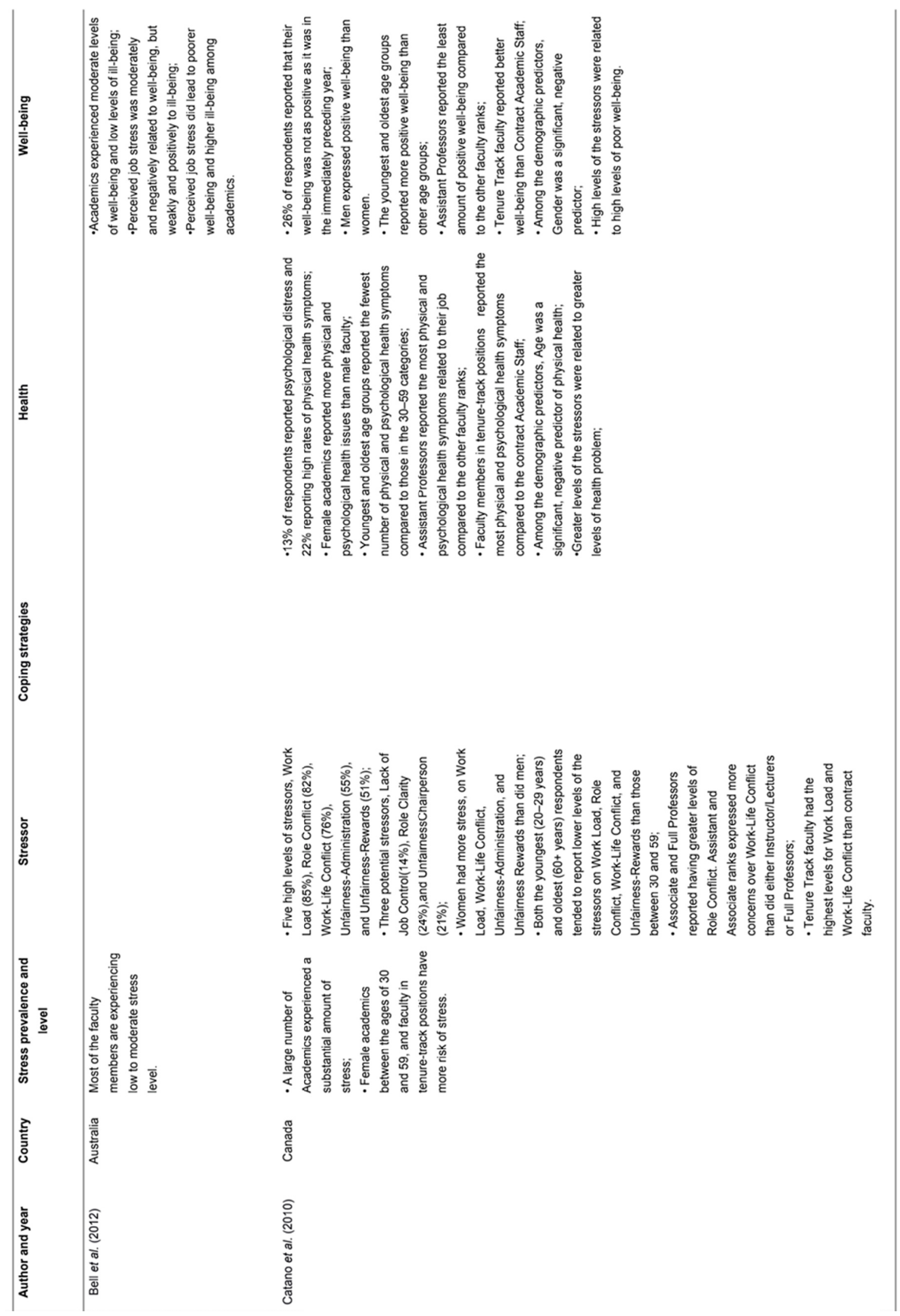




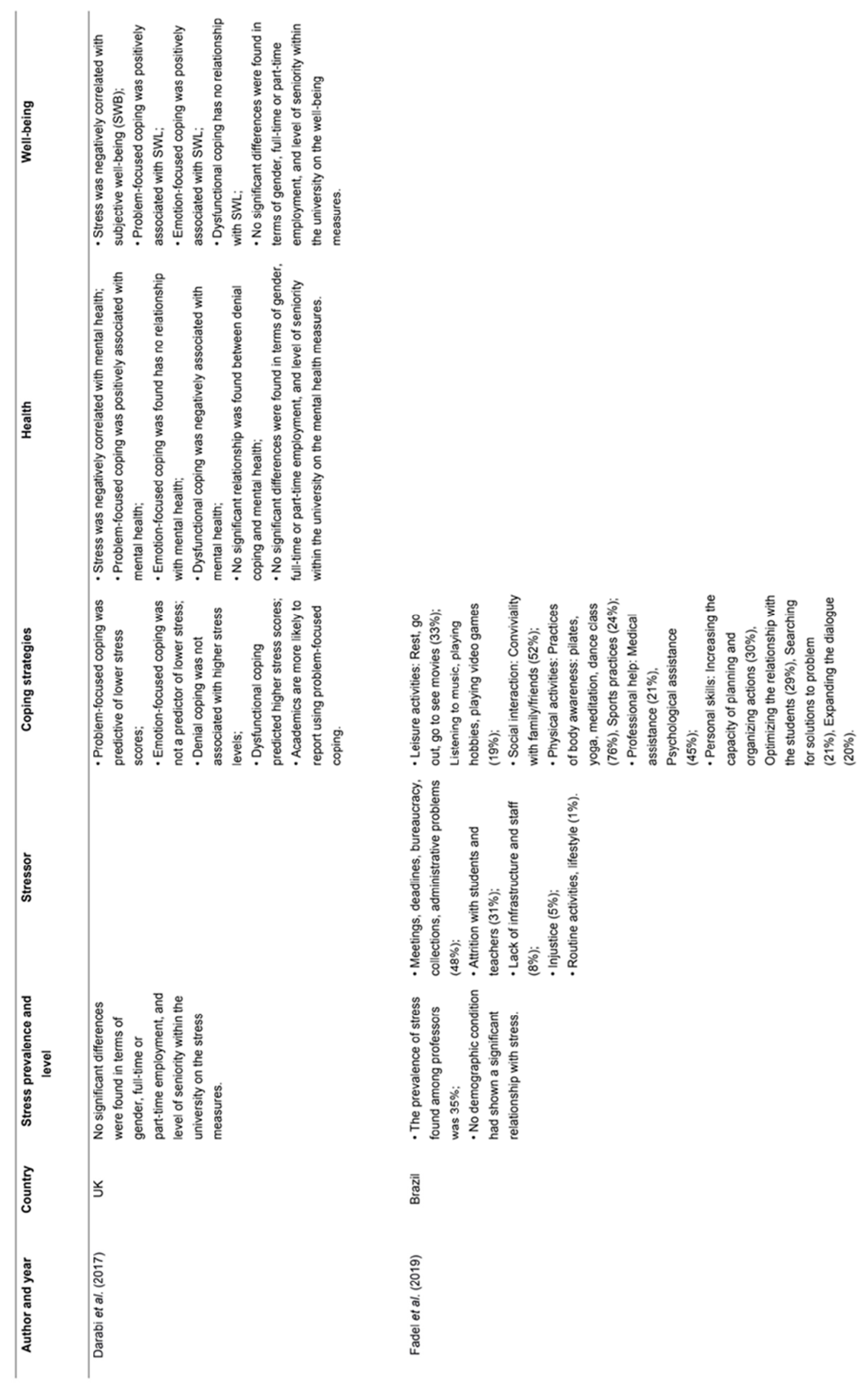




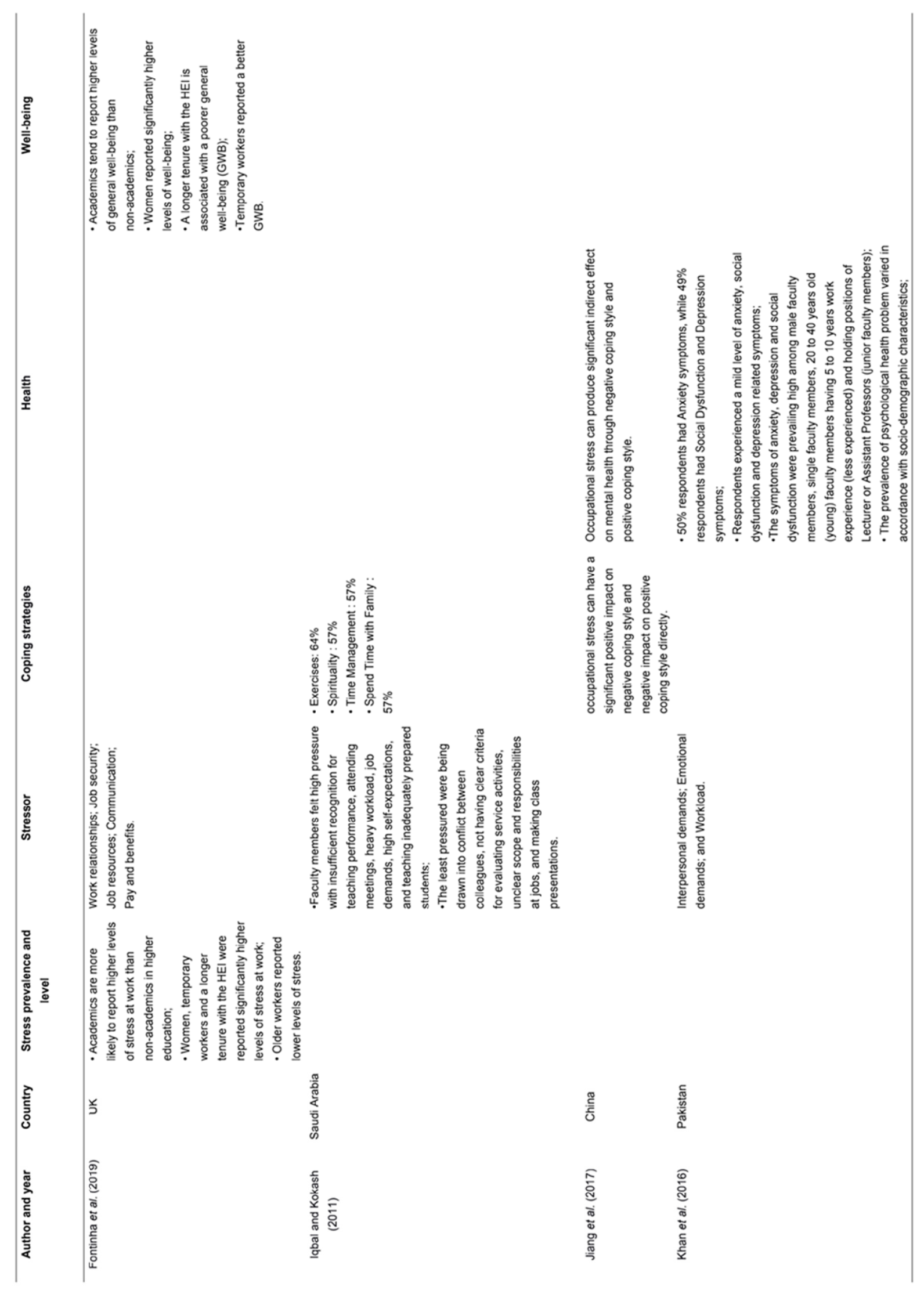




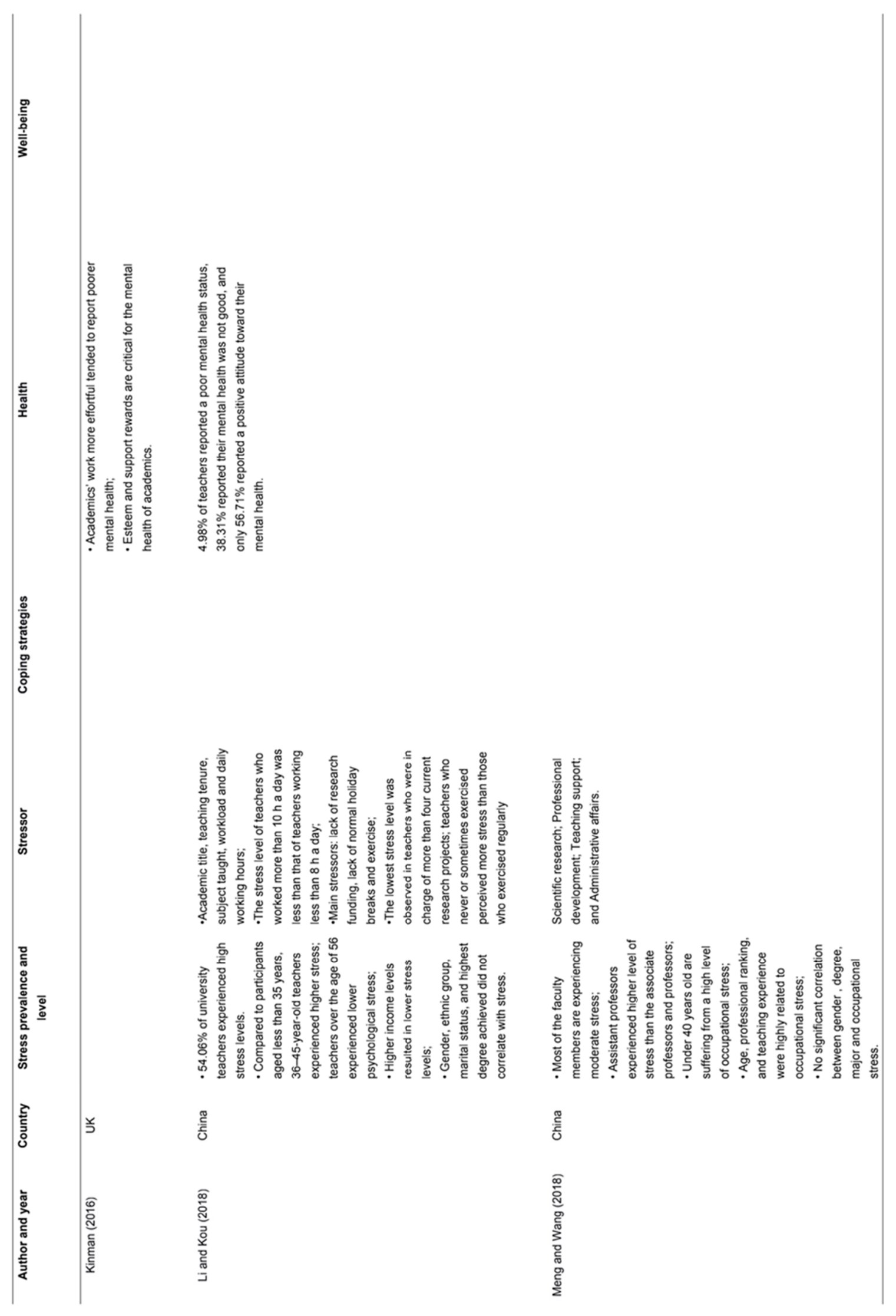




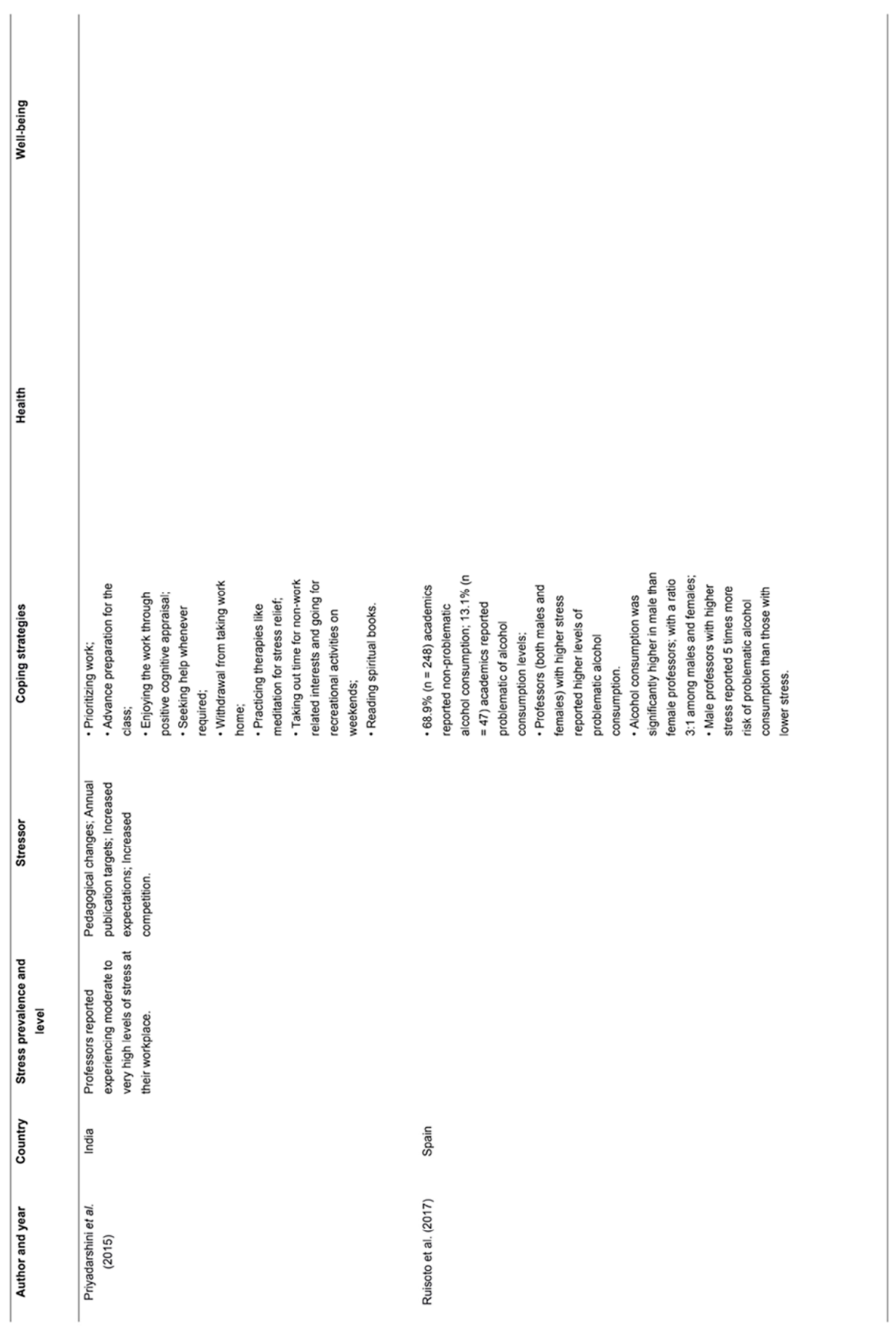




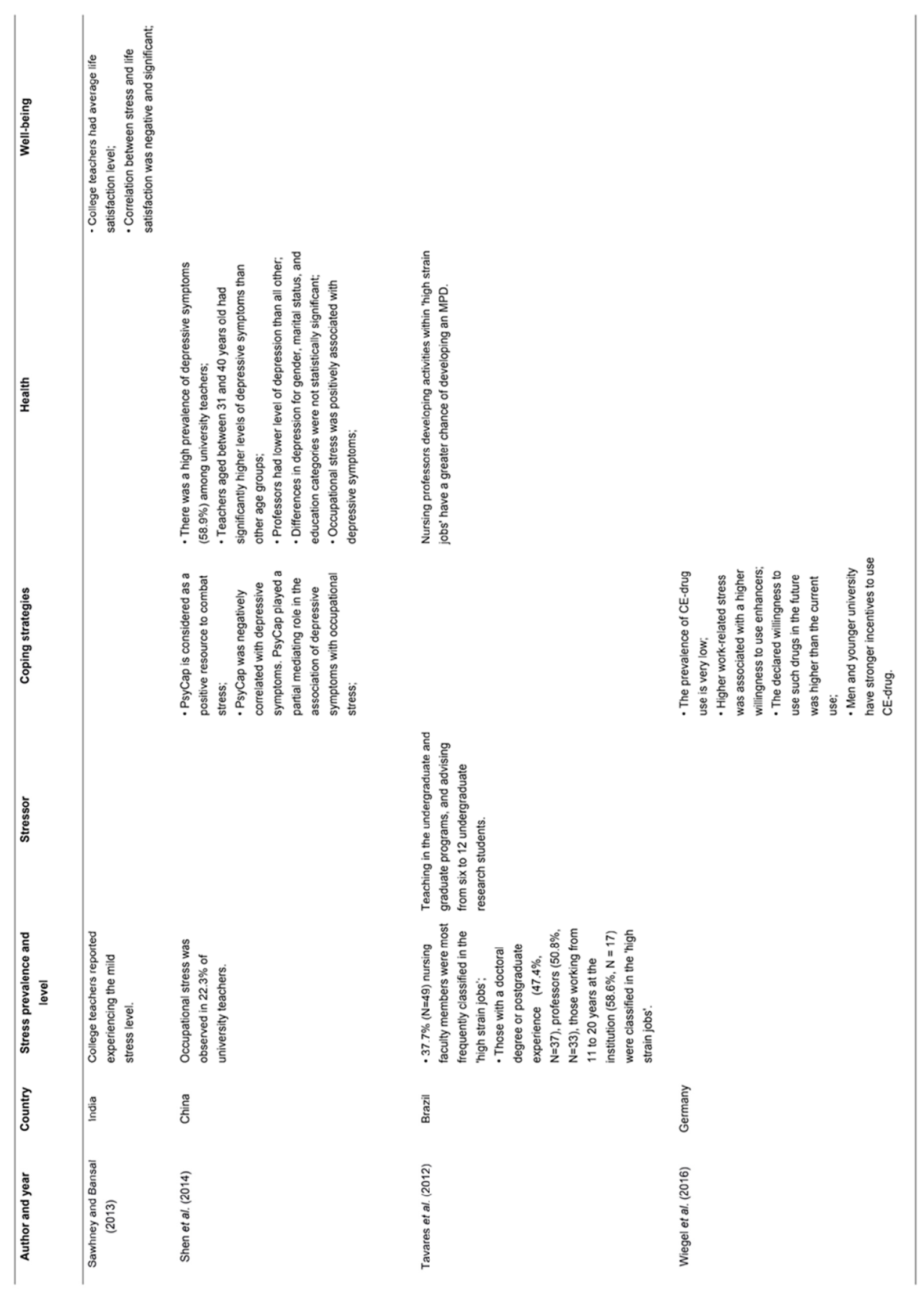




\section{Copyrights}

Copyright for this article is retained by the author(s), with first publication rights granted to the journal.

This is an open-access article distributed under the terms and conditions of the Creative Commons Attribution license (http://creativecommons.org/licenses/by/4.0/). 